\title{
Glucocorticoid Anorexia in Rats
}

\author{
C. WAYNE SIMPSON, LEO V. DICARA AND GEORGE WOLF \\ Department of Psychiatry, Mental Health Research Institute, The University of Michigan \\ Ann Arbor, Michigan
}

AND

State University of New York, Purchase, New York

(Received 21 September 1973)

\begin{abstract}
SIMPSON, C. W., L. V. DICARA AND G. WOLF. Glucocorticoid anorexia in rats. PHARMAC. BIOCHEM. BEHAV. 2(1) 19-25, 1974. - The effects of two mineralocorticoids, two glucocorticoids and a compound possessing both activities on ad lib food intake, water intake and salt intake were investigated. Dose response curves for $d$-aldosterone, DOCA, 9 alpha fluorocortisone, corticosterone and dexamethasone were obtained following subcutaneous injections in different groups of rats. Results support the conclusion of a clear separation between the mineralocorticoids and glucocorticoids in terms of their effects on salt intake and food intake respectively. In general (but with some notable exceptions) glucocorticoid activity was associated with anorexia while mineralocorticoid activity was associated with enhanced salt appetite, and the two effects appeared entirely independent of each other. Single doses of dexamethasone and 9 alpha flurocortisone significantly reduced $(p<0.0001) 24 \mathrm{hr}$ ad lib food intakes and body weights for several post injection days. Conversely, d-aldosterone, DOCA, 9 alpha flurocortisone, and corticosterone all significantly $(p<0.001)$ increased salt intakes for 1 or more post injection days. The glucocorticoid data are discussed in terms of a possible modification of arterial-venous glucose utilization differences affecting hypothalamic sites or the possible activation of glucose sensitive hepatic cells.
\end{abstract}

Glucocorticoid anorexia Satiety Glucose receptors Hypothalamic sites Hepatic cells

IMPORTANT behavioral actions of adrenal steroids are being elucidated by researchers in several allied fields. These behavioral actions seem to fall into two general classes - reactions to external stresses and alimentary responses. The literature demonstrating the profound interactions between stress situations and adrenocortical function is large and impressive and is the subject of a recent review $[3,4]$. Less work has been done on alimentary effects of the adrenocortical hormones and this is the topic of the present paper.

There is evidence that exogenous ACTH enhances learned behavior reinforced by food or water $[6,10,11]$ but it is not clear whether the enhancement is due to a specific increase in motivation or a non-specific increase in activity. Several investigators have noted a loss of body weight following treatment with a synthetic glucocorticoid (dexamethasone) and it has been suggested that this is related to an increase in general activity $[1,2,3$, 5 ]. The most frequently reported result following mineralocorticoid injection is a specific increase in sodium intake and a secondary increase in water intake [16], [21]. In a recent study, Wolf, McGovern and DiCara [22], a synthetic steroid, 9 alpha flurocortisone (9 alpha F) $[8,20]$, which has potent mineralocorticoid and glucocorticoid properties, was studied with regard to its sodium appetite inducing properties. It was incidentally noted that food intake decreased after injection. The anorectic effect seemed to appear about one day following a large increase in sodium intake and had a duration of from 2 to 4 days thereafter. It seemed plausible to hypothesize that the diminution in food intake was secondary to disruptions in body fluid balance resulting from the increased sodium intake coupled with increased renal sodium retention.

In the first experiment presented here food intake was measured in two groups of 9 alpha $F$ treated rats. One group had access to supplementary sodium and the other group did not. In the second experiment the effects of several natural and synthetic corticoids possessing various degrees of mineralocorticoid and glucocorticoid activity upon food, water and salt intake was assessed.

The study of the alimentary effects of adrenal steroids is considered to be of potentially great importance for three reasons. First, it may reveal natural behavioral con-

${ }^{1}$ This work was supported by Grant MH 21403 from the United States Public Health Service and 71797 from the American Heart Association to Leo V. DiCara. 


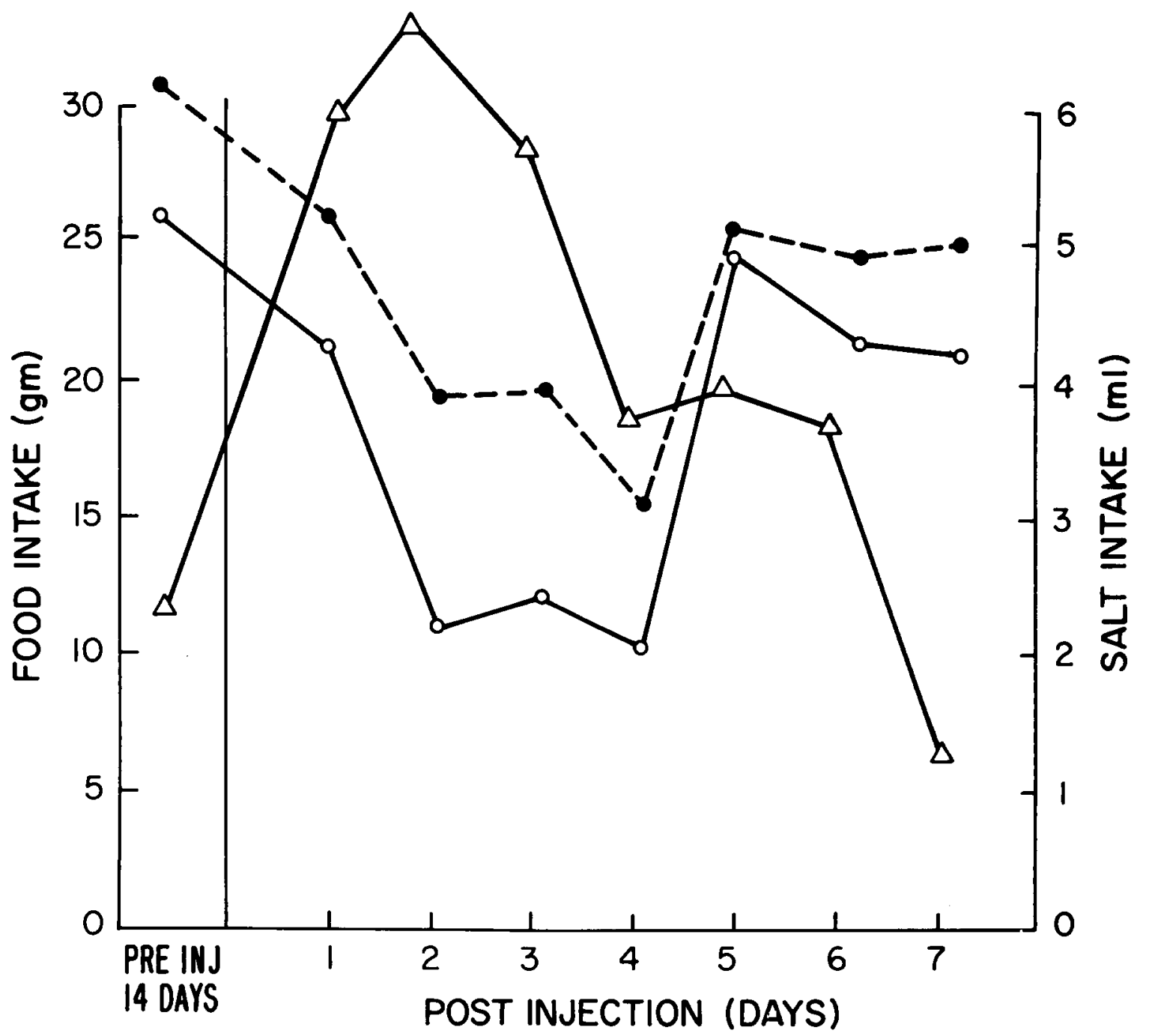

FIG. 1. Mean food intakes for two groups of rats given a single subcutaneous injection $5 \mathrm{mg}$ of 9 alpha Flurocortisone. Mean salt intakes for rats from Group 2 are also represented. Shown are means for 14 pre-injection control days and 7 post-injection days measured. •-- $\bullet$ Group 1 without salt,

$\triangle$ Group 2 with salt, $\triangle \longrightarrow \triangle$ salt intakes for Group 2.

trol actions associated with the homeostatic functions of the adrenal cortex. Second, the data when integrated with the known physiological actions of the corticoids may shed light on the mechanism of action of alimentary control systems. Third, demonstration of a specific anorectic effect of certain steroids may lead to the development of pharmacologic agents useful for human dietary control.

\section{EXPERIMENT 1}

\section{Method}

Animals. Sixteen male albino rats (Spartan) weighing between 300-400 g served in Experiment 1.

Procedures. Two groups of 8 animals, randomly assigned to each group, were formed. All rats were then given $24 \mathrm{~h}$ ad lib access to Borden undiluted condensed milk for 14 days to establish stable baseline intakes. Animals in both groups also had ad lib tap water presented in
Wahmann graduated cylinders. In additon, rats in Group 2 were presented with a $0.5 \mathrm{M} \mathrm{NaCl}$ solution ad lib from a graduated Wahmann drinking tube. Food, water, and salt intakes and body weights were measured daily.

On Day 15 all rats received a single injection of $5 \mathrm{mg} 9$ alpha $F$ suspended in sesame oil. The injection was in a volume of $0.5 \mathrm{ml}$ subcutaneously.

Intake data were analyzed for each post injection day by the $t$-test for correlated observations until the 1 st post injection day which did not differ significantly from baseline intake values.

\section{Results}

Figure 1 shows mean food intake of the two groups for the 14 day pre-injection period and for each of the 7 post-injection days. Food intakes of both groups followed very similar patterns during the post-injection period. There was a small non-significant decrease of food intake 
( $5 \mathrm{~g})$, on the first post-injection day followed by a large (2 to 3 fold decrease) persisting for the next 3 days, Group $1(p<0.001)$ and Group $2(p<0.001)$, and a return to normal values on the final 3 days. The salt intake of the group given supplementary $0.5 \mathrm{M}$ saline increased from a pproximately $2 \mathrm{ml}$ per day during the pre-injection period to about $6 \mathrm{ml}$ per day on the first three postinjection days $(p<0.02)$ and then gradually receded to normal values during the subsequent 4 days as seen in Fig. 1. Water intakes tended to increase and body weights to decrease following injection but to avoid redundancy these data shall not be discussed further here because they are presented in detail in the more comprehensive experiment which follows.

\section{EXPERIMENT 2}

The preceding study showed very clearly that the diminution of food intake following 9 alpha $F$ treatment is independent of its effects on sodium intake. The purpose of this experiment is to compare the effects of graded doses of several natural and synthetic corticoids upon food, water, and salt intake and body weight. Since the corticoids used differ widely in their relative activity upon mineral and glucose metabolism, the experiment sheds light upon which of these two functions of corticoids is responsible for the anorexia.

\section{Method}

Animals. Thirty adult male Sprague-Dawley rats of the Spartan strain weighing between $300-400 \mathrm{~g}$ served in this experiment.

Procedure. All animals were given $24 \mathrm{hr}$ ad lib access to Borden's undiluted sweetened condensed milk for 14 days to establish stable intakes. In addition each rat also had $24 \mathrm{hr}$ ad lib access to a $1.0 \mathrm{M} \mathrm{NaCl}$ solution and tap water both presented in Wahmann graducated cylinders. Following the 14 day adaptation period rats were randomly distributed to form 5 groups of 6 animals each. Intakes and body weights were measured daily.

Independent groups of animals received injections of one of 5 corticoids in an ascending series of dosages. Dose-response curves were obtained for all groups under the particular drug for that group. Drugs used were: daldosterone, DOCA, 9 alpha F, corticosterone and dexamethasone. All drugs were suspended in sesame oil immediately before injection. Injections were in volumes of $0.5 \mathrm{cc}$ given subcutaneously. A variable number of post-injection days (from 4-18) followed each injection until a correlated $t$-test revealed no significant differences in intake from control levels. The next dose in the variable series was injected at that time. All rats received a total of 4 injections.

Intake measures within a particular drug level were

\section{TABLE 1}

DOSE-RESPONSE FOR FOOD INTAKES FOLLOWING INJECTION WITH 9 ALPHA F. TABLED VALUES REPRESENT ABSOLUTE MEAN INTAKES FOR THE PRE-INJECTION CONTROL PERIOD, AND ALL POST-INJECTION DAYS MEASURED.

\begin{tabular}{|c|c|c|c|c|c|c|c|c|}
\hline \multirow[t]{2}{*}{9 Alpha F } & \multicolumn{2}{|c|}{$400 \mu \mathrm{g}$} & \multicolumn{2}{|c|}{$1.2 \mathrm{mg}$} & \multicolumn{2}{|c|}{$3.6 \mathrm{mg}$} & \multicolumn{2}{|c|}{$10.8 \mathrm{mg}$} \\
\hline & $\overline{\mathrm{X}}$ & S.D. & $\overline{\mathrm{X}}$ & S.D. & $\overline{\mathrm{X}}$ & S.D. & $\overline{\mathrm{X}}$ & S.D. \\
\hline Control & 28.38 & 3.20 & 28.38 & 3.20 & 28.38 & 3.20 & 28.38 & 3.20 \\
\hline Post 1 & 29.50 & 2.92 & 26.43 & 3.37 & 20.33 & $6.41+$ & 23.30 & 9.31 \\
\hline Post 2 & 31.28 & 2.32 & 27.31 & 1.67 & 15.48 & $4.24 \ddagger$ & 16.30 & $12.40 \ddagger$ \\
\hline Post 3 & 28.35 & 4.48 & 24.08 & 3.73 & 18.83 & $3.34 \ddagger$ & 12.90 & $8.06 \ddagger$ \\
\hline Post 4 & 28.50 & 3.17 & 25.73 & 2.48 & 19.91 & $3.78+$ & 15.90 & $7.56 \ddagger$ \\
\hline Post 5 & 27.28 & 2.88 & 26.21 & 2.48 & 17.86 & $5.00 \div$ & 18.30 & $7.60 \dagger$ \\
\hline Post 6 & & & & & 19.00 & $4.77 \ddagger$ & 21.30 & $9.76^{*}$ \\
\hline Post 7 & & & & & 20.7 & $6.71 \ddagger$ & 10.4 & $21.76 \ddagger$ \\
\hline Post 8 & & & & & 20.1 & $3.37 \ddagger$ & 24.0 & 10.15 \\
\hline Post 9 & & & & & 18.53 & $4.44 \ddagger$ & 21.6 & $22.26 *$ \\
\hline Post 10 & & & & & 21.18 & $3.69 \neq$ & 22.3 & 9.75 \\
\hline Post 11 & & & & & 20.68 & $2.66 \neq$ & 21.7 & $5.54 *$ \\
\hline Post 12 & & & & & 26.00 & 3.33 & 21.1 & $7.84 *$ \\
\hline Post 13 & & & & & 21.20 & $4.67+$ & 19.5 & $9.59 \dagger$ \\
\hline Post 14 & & & & & 23.76 & 5.45 & 20.9 & $6.54 *$ \\
\hline Post 15 & & & & & 23.18 & $1.95^{*}$ & 19.1 & $6.53 \dagger$ \\
\hline Post 16 & & & & & 25.90 & 3.33 & & \\
\hline
\end{tabular}

$$
{ }^{*} p<0.05 \quad \dagger p<0.02 \quad \ddagger p<0.01
$$


TABLE 2

MEAN FOOD INTAKES FOLLOWING THREE DIFFERENT DOSES OF DEXAMETHASONE FOR CONTROL AND ALL POST-INJECTION DAYS

\begin{tabular}{|c|c|c|c|c|c|c|}
\hline \multirow[t]{2}{*}{ Dexamethasone } & \multicolumn{2}{|c|}{$400 \mu \mathrm{g}$} & \multicolumn{2}{|c|}{$1.2 \mathrm{mg}$} & \multicolumn{2}{|c|}{$3.6 \mathrm{mg}$} \\
\hline & $\overline{\mathrm{X}}$ & S.D. & $\bar{X}$ & S.D. & $\overline{\mathrm{X}}$ & S.D. \\
\hline Control & 29.44 & 1.77 & 29.44 & 1.77 & 29.44 & 1.77 \\
\hline Post 1 & 30.08 & 4.02 & 35.04 & 5.28 & 26.48 & 3.32 \\
\hline Post 2 & 11.34 & $3.57 \ddagger$ & 14.98 & $5.30 \ddagger$ & 15.26 & $3.31 \ddagger$ \\
\hline Post 3 & 11.94 & $1.81 \ddagger$ & 21.76 & $5.13+$ & 14.04 & $1.55 \ddagger$ \\
\hline Post 4 & 23.78 & $4.85 \ddagger$ & 25.30 & 4.50 & 12.78 & $2.79 \ddagger$ \\
\hline Post 5 & 22.20 & $3.09 \neq$ & 27.70 & 2.55 & 13.02 & $4.87 \ddagger$ \\
\hline Post 6 & 31.22 & 3.49 & & & 12.96 & $2.23 \neq$ \\
\hline Post 7 & & & & & 13.70 & $3.17 \ddagger$ \\
\hline Post 8 & & & & & 15.30 & $3.32+$ \\
\hline Post 9 & & & & & 16.68 & $2.92 \ddagger$ \\
\hline Post 10 & & & & & 15.40 & $3.79 \neq$ \\
\hline Post 11 & & & & & 16.96 & $5.54 \ddagger$ \\
\hline Post 12 & & & & & 18.42 & $7.08+$ \\
\hline Post 13 & & & & & 15.72 & $7.01 \ddagger$ \\
\hline Post 14 & & & & & 14.76 & 4.27 \\
\hline Post 15 & & & & & 17.48 & $5.20 \ddagger$ \\
\hline Post 16 & & & & & 20.44 & $4.55 \neq$ \\
\hline Post 17 & & & & & 21.98 & $5.06 \neq$ \\
\hline Post 18 & & & & & 16.58 & $2.31 \ddagger$ \\
\hline Post 19 & & & & & 20.26 & $6.33 \neq$ \\
\hline Post 20 & & & & & 21.48 & $6.91 末$ \\
\hline Post 21 & & & & & 24.30 & 7.98 \\
\hline
\end{tabular}

$\ddagger p<0.01$

computer (IBM 360) analyzed first by analysis of variance. If the overall $\mathrm{F}$ ratio was significant, i.e., $p<0.05$, then Sheffe's test for simultaneous contrasts was used to analyze pairwise comparisons.

\section{Results}

Food Intake. Table 1 shows mean food intakes for 9 alpha $\mathrm{F}$ at four different dosages and for all post-injection days measured. Food intakes were not significantly altered ( $p>0.05$ ) following injections of $400 \mu \mathrm{g}$ or $1.2 \mathrm{mg} 9$ alpha F. Analysis of variance showed a significant $(p<0.0001)$ depression in food intakes at $3.6 \mathrm{mg}$; however, and the effect lasted 13 of 15 post-injection days following this single injection. The highest dose, $10.8 \mathrm{mg}$, also significantly $(p<0.01)$ decreased food intakes overall and for 12 of 14 post-injection days.

All dose levels of dexamethasone produced significant anorexia in rats in this treatment group as seen in Table 2. Four hundred $\mu \mathrm{g}$ significantly $(p<0.0001)$ decreased food intakes and continued its depressing effects on 4 of 5 postinjection days with probabilities ranging between $(p<0.01)$ and $(p<0.0001) .1 .2 \mathrm{mg}$ 's significantly decreased $(p<0.0001)$ food intakes on the injection day and 2 of 4 post-injection days. The highest dose of dexamethosone tested, $3.6 \mathrm{mg}$, reproduced more profoundly the anorexia seen with lower doses. The analysis of variance showed significantly lower $(p<0.00001)$ intakes overall and for 17 of 18 post-injection days with probabilities ranging between $(p<0.00001)$ and $(p<0.008)$. The decreases seen with both 9 alpha $F$ and dexamethasone were not only highly reliable but substantial, reducing absolute food intakes more than $50 \%$.

Neither d-aldosterone, corticosterone nor DOCA generally affected food intakes at any of the doses injected, as shown in Tables 3,4 and 5 respectively. However, for some reason, DOCA at a dose of $3.6 \mathrm{mg}$ did significantly $(p<0.04)$ decrease food intakes as determined from the analysis of variance. Sheffe's test showed two of nin postinjection days were signficantly reduced with probabilities 
TABLE 3

DOSE-RESPONSE ANALYSIS OF MEAN FOOD INTAKES FOLLOWING FOUR INJECTIONS OF CORTICOSTERONE. INTAKES ARE INCLUDED FOR CONTROL AND ALL POSTINJECTION DAYS.

\begin{tabular}{|c|c|c|c|c|c|c|c|c|}
\hline \multirow[t]{2}{*}{ Corticosterone } & \multicolumn{2}{|c|}{$400 \mu \mathrm{g}$} & \multicolumn{2}{|c|}{$1.2 \mathrm{mg}$} & \multicolumn{2}{|c|}{$3.6 \mathrm{mg}$} & \multicolumn{2}{|c|}{$10.8 \mathrm{mg}$} \\
\hline & $\overline{\mathrm{X}}$ & S.D. & $\overline{\mathrm{X}}$ & S.D. & $\overline{\mathrm{X}}$ & S.D. & $\overline{\mathrm{X}}$ & S.D. \\
\hline Control & 28.60 & 4.03 & 28.60 & 4.03 & 28.60 & 4.03 & 28.60 & 4.03 \\
\hline Post 1 & 26.76 & 4.35 & 27.61 & 5.36 & 27.86 & 4.53 & 27.55 & 4.79 \\
\hline Post 2 & 28.98 & 4.22 & 27.60 & 5.44 & 29.15 & 6.23 & 27.63 & 6.32 \\
\hline Post 3 & 27.70 & 3.90 & 27.26 & 4.86 & 27.01 & 6.09 & 27.71 & 5.60 \\
\hline Post 4 & 28.03 & 6.79 & 28.48 & 6.52 & 26.61 & 4.99 & 26.41 & 2.00 \\
\hline Post 5 & 27.70 & 5.74 & 27.01 & 7.36 & 26.53 & 4.85 & 25.81 & 1.78 \\
\hline Post 6 & & & & & & & 28.70 & 2.60 \\
\hline Post 7 & & & & & & & 34.51 & 8.59 \\
\hline
\end{tabular}

\section{TABLE 4}

MEAN FOOD INTAKES RECORDED FOLLOWING FOUR DIFFERENT DOSES OF DOCA. INCLUDED ARE PRE-INJECTION CONTROL VALUES AND ALL POST-INJECTION DAYS MEASURED.

\begin{tabular}{|c|c|c|c|c|c|c|c|c|}
\hline \multirow[t]{2}{*}{ DOCA } & \multicolumn{2}{|c|}{$400 \mu \mathrm{g}$} & \multicolumn{2}{|c|}{$1.2 \mathrm{mg}$} & \multicolumn{2}{|c|}{$3.6 \mathrm{mg}$} & \multicolumn{2}{|c|}{$10.8 \mathrm{mg}$} \\
\hline & $\overline{\mathrm{X}}$ & S.D. & $\overline{\mathrm{X}}$ & S.D. & $\overline{\mathrm{X}}$ & S.D. & $\overline{\mathrm{X}}$ & S.D. \\
\hline Control & 29.56 & 2.38 & 29.56 & 2.38 & 29.56 & 2.38 & 29.56 & 2.38 \\
\hline Post 1 & 30.28 & 2.69 & 27.98 & 3.16 & 25.70 & $5.88^{*}$ & 21.55 & 5.64 \\
\hline Post 2 & 29.36 & 5.11 & 30.63 & 5.78 & 28.86 & 4.08 & 25.36 & 3.07 \\
\hline Post 3 & 31.11 & 3.60 & 28.60 & 3.88 & 26.18 & 3.17 & 24.01 & 4.78 \\
\hline Post 4 & 29.21 & 4.49 & 27.81 & 4.10 & 28.88 & 6.38 & 27.50 & 2.68 \\
\hline Post 5 & 27.91 & 4.52 & 27.45 & 4.80 & 26.18 & 4.84 & 25.43 & 3.24 \\
\hline Post 6 & & & & & & & 25.33 & 4.03 \\
\hline Post 7 & & & & & & & 27.41 & 6.69 \\
\hline
\end{tabular}

$$
* p<0.05
$$

of $(p<0.009)$ and $(p<0.001)$ respectively. However, this effect is probably unreliable because higher and lower doses do not significantly affect food intakes.

As would be expected from the food intake data body weights were significantly decreased following injections with 9 alpha $F$ and dexamethasone. All doses dexamethasone significantly altered body weights in this group, with decreases ranging from 9 to $23 \%$. Four hundreed $\mu \mathrm{g}$ 's, $1.2 \mathrm{mg}$ 's and $3.6 \mathrm{mg}$ 's all significantly reduced body weights with probabilities of $(p<0.01),(p<0.005)$ and $(p<0.02)$ respectively as determined using the $t$-test for correlated observations. Only the highest dose of 9 alpha F $10.8 \mathrm{mg}$ resulted in significantly $(p<0.01)$ reduced body weights as revealed by the $t$-test for correlated observations. None of the other corticoids tested, corticosterone, d-aldosterone or
DOCA significantly affected body weight at any of the doses tested.

Water and salt intake. Water intakes were highly variable following all drugs. Although some increases were observed, these increases did not reach signficance because of the high variability of the measurements. All corticoids except dexamethasone caused significant intreases in salt intake at one or more dosage levels as reported in several previous studies [7].

\section{DISCUSSION}

The data from Experiment 1 shows clearly that the anoxeric action of 9 alpha $F$ on ad lib food intake is independent of its capacity to increase salt intake. Rats with salt available both increased salt intakes and decreased ad 
TABLE 5

MEAN FOOD INTAKE VALUES FOR CONTROL DAYS AND ALL POST-INJECTION DAYS FOLLOWING 4 INJECTIONS OF d-ALDOSTERONE

\begin{tabular}{|c|c|c|c|c|c|c|c|c|}
\hline \multirow[t]{2}{*}{ d-ALDO } & \multicolumn{2}{|c|}{$400 \mu \mathrm{g}$} & \multicolumn{2}{|c|}{$1.2 \mathrm{mg}$} & \multicolumn{2}{|c|}{$3.6 \mathrm{mg}$} & \multicolumn{2}{|c|}{$10.8 \mathrm{mg}$} \\
\hline & $\bar{X}$ & S.D. & $\bar{x}$ & S.D. & $\overline{\mathrm{X}}$ & S.D. & $\overline{\mathrm{X}}$ & S.D. \\
\hline Control & 26.00 & 5.01 & 26.00 & 5.01 & 26.00 & 5.01 & 26.00 & 5.01 \\
\hline Post 1 & 29.63 & 2.99 & 28.86 & 4.83 & 23.73 & 5.67 & 21.08 & 5.70 \\
\hline Post 2 & 28.05 & 6.68 & 30.70 & 3.63 & 26.01 & 4.62 & 22.98 & 4.47 \\
\hline Post 3 & 27.56 & 4.78 & 28.85 & 4.23 & 26.88 & 4.79 & 21.10 & 5.58 \\
\hline Post 4 & 27.38 & 5.51 & 28.63 & 7.20 & 27.98 & 7.76 & 18.56 & 4.25 \\
\hline Post 5 & 26.05 & 4.26 & 29.38 & 3.50 & 28.56 & 13.40 & 22.06 & 3.70 \\
\hline Post 6 & & & & & & & 24.11 & 2.58 \\
\hline Post 7 & & & & & & & 23.60 & 5.24 \\
\hline
\end{tabular}

lib food intakes following a single injection of 9 alpha $F$. Ad lib fed rats without salt available showed exactly the same anoxeric response to this same dose of 9 alpha $F$. The results of the dose-response studies in Experiment 2 also suggests that a clear separation of function exists between the glucocorticoids and mineralocorticoids. The synthetic steroid 9 alpha $F$ has high relative potencies in terms of sodium retention and liver glycogen deposition and this compound significantly elevated salt intakes and significantly decreased food intakes at two dose levels. Dexamethasone which is almost devoid of mineralocorticoid activity produced profound and long lasting decreases in food intake at all doses tested following single injections. Water and salt intakes, however, were unaffected of any concentration of dexamethasone. The results of the corticosterone injections do not fit quite so neatly into the mineral-glucocorticoid differentiation. Although classified as a glucocorticoid, corticosterone has modest sodium retention activity and relatively weak liver glycogen activity. While the sodium retention potencies of corticosterone are many times less than those of 9 alpha F, D-aldosterone or DOCA, this steroid significantly increased salt intakes in Experiment 2. No dose of corticosterone tested significantly altered $24 \mathrm{hr}$ food intakes, and it is interesting to note that corticosterone is essentially no more potent than aldosterone in terms of liver glycogen deposition. As mentioned previously aldosterone was ineffective in modifying food intakes at any dose tested. While all injections of both mineralocorticoids and glucocorticoids are well above the daily secretion rates of the endogenous steroids, it is important to emphasize the differential effects on feeding noted in the results. Corticosterone even at clearly pharmacological concentrations $10.8 \mathrm{mg}$ still did not significantly alter $24 \mathrm{hr}$ food intakes. Neither aldosterone nor DOCA at the same concentration significantly effected daily food intake. Both synthetic glucocorticoids 9 alpha $F$ and dexamethasone however, at much lower concentrations 9 alpha F, $3.6 \mathrm{mg}$, and dexamethasone $400 \mu \mathrm{g}$ significantly decreased food intakes for several post injection days. It would appear more probable therefore that the anoxeric responses to 9 alpha $F$ and dexamethesone is more closely related to possible disruptions of carbohydrate, protein and/or amino acid metabolism rather than alterations of endogenous steroid secretion rates. The results of these studies support the conclusions that mineralocorticoids can elicit increased salt appetite without anorexia and the glucocorticoids can produce significant decreases in food intake without elevations in salt intake.

The fact that one of the major actions of glucocorticoids on carbohydrate metabolism is the increased production of glucose [9] suggests at least two possible alternatives to account for the decreases in food intake observed in these experiments. From the earliest statement of the glucostatic theory [12] the difference in A-V glucose utilization has been widely accepted as the mechanism responsible for the regulation of food intake. A large body of literature including both central and peripheral injections of glucose support the notion of glucose sensitive central mechanisms involved in food regulation. Oomura and his associates [14,15] using electrophysiological and microelectrophoretic techniques have discussed the existence of reciprocally connected glucose sensitive systems in the ventromedial and ventrolateral areas of the hypothalamus. Epstein and his associates [19] have used a glucose analogue, 2-Deoxy-d-glucose, to create a glucoprivation in central cells and have observed increases in food intakes following these manipulations. We might speculate that our glucocorticoid injections significantly altered the pattern of A-V glucose utilization for several days. These changes might then be monitored by glucose sensitive cells in the ventromedial area of the hypothalamus. Increased activity from these supposedly satiety neurons would then inhibit activity from ventrolateral feeding neurons resulting in a significant decrease in food intake.

An alternative explanation of our results is related to the hepatic glucose receptor system described by Russek [17]. Russek [17] has reported profound and extended anorexia following various glucose loads in dogs. Niijima [13] has also demonstrated changes in electrophysiologically recorded activity from hepatic cells as a consequence of glucose 
challenge. According to Russek [18], information from these hepatic glucose sensitive cells could then be relayed over vagal and other afferents to hypothalamic areas. The glucocorticoids might directly affect the glucose sensitive hepatic cells described by Russek. This explanation is increasingly plausbile when it is recalled that one of the major actions of the glucocorticoids is the deposition of liver glycogen at liver sites. A problem for both glucose sensitive systems is the relative time course of the effects observed by us. Either central or peripheral glucose producing anorexia and 2-deoxy-d-glucose elicited eating following central or peripheral administration are short term effects. All studies report intakes returning to normal within $24 \mathrm{hr}$. Our animals, however, while not debilitated, continued to eat less and lose weight for as long as 20 days following a single subcutaneous injection. Although our data cannot estimate the relative time course of metabolic effects following the injections, a recent study by Elliott, Peters and White [5] does provide some information concerning dexamethasone. They reported a significant reduction in the amino-acid incorporating ability of rat skeletal muscle ribosomes in vitro following injection with glucocorticoids including dexamethasone. Diminished ribosomal activity was observed $48 \mathrm{hr}$ following a $150 \mu \mathrm{g}$ dose of dexamethasone i.p. This study also demonstrates the profound effects of glucocorticoids on protein and amino-acid metabolism and suggests another alternative as the possible mediator of the observed anorexic responses. Clearly more experiments are necessary to resolve the relative contributions of protein, hepatic, and hypothalamic mechanism responsible for glucocorticoid induced anorexia.

\section{REFERENCES}

1. Beatty, P. A., W. W. Beatty, R. E. Bowman and R. E. Gilchrist. The effects of ACTH, adrenolectomy and dexame thasone on the acquisition of an avoidance response. Physiol. Behav. 5: 939-944, 1970 .

2. Beatty, W. C., C. W. Scoriten and P. A. Beatty. Differential effects of dexamethasone and body weight loss on two measures of activity. Physiol. Behav. 7: 869-872, 1971.

3. Bohus, B. and K. Lissak. Adrenocortical hormones and avoidance behavior of rats. Int. J. Neuropharm. 7: 301-306, 1968 .

4. Brain, Paul F. Mammalian behavior and the adrenal cortex. A Review. Behav. Biol. 7: 453-477, 1972.

5. Elliott, P., R. F. Peters and A. M. White. A study of the relationship between Glucocorticoid-induced weight loss in rats and the activity of skeletal-muscle and cardiac muscle ribosomes in vitro. Proc. Biochem. Soc. 125: 106-107, 1971.

6. Endröczi, E. and K. Lissak. Spontaneous goal-directed motor activity related to the alimentary conditioned reflex behavior and its regulation by neural and humoral factors. Acta physiol. hung. 265-283, 1962.

7. Fregly, M. J. and I. W. Waters. Hormonal regulation of the spontaneous sodium chloride appetite of" rats. In: Olfaction and Taste II, edited by T. Hayashi, Peramon Press, 1967, pp. 439-458.

8. Fried, $J$. Biological effects of 9-alpha-Florohydrocortisone and related Halogenated steroids in animals. Ann. N. Y. Acad. Sci. 61: $573-581,1955$.

9. Goodman, L. S. and A. Gilman. The Pharmacological Basis of Therapeutics. 3rd ed., MacMillan Co., 1619, 1965.

10. Gray, J. A. Effect of ACTH on extinction of rewarded behavior is blocked by previous administration of ACTH. Nature 229: 52-54, 1971 .

11. Guth, S., S. Levine and J. P. Seward. Appetitive acquisition and extinction effects with exogenous ACTH. Physiol. Behav. 7: $195-200,1971$.
12. Mayer, J. Regulation of energy intake and body weight. The glucostatic theory and the lipostatic hypothesis. Ann. N. Y. Acad. Sci. 63: 15-43, 1955.

13. Niijima, A. Afferent impulse discharges from glucoreceptors in the liver of the guinea pig. Ann. N. Y. Acad. Sci 157:690-700, 1969.

14. Oomura, Y., H. Ooyama and F. Naka. Reciprocal relationship of the lateral and ventromedial hypothalamus in the regulation of food intake. Physiol. Behav. 2: 97-117, 1967.

15. Oomura, Y., T. Ono, H. Ooyama and M. J. Wayner. Glucose and osmosensitive neurons of the rat hypothalamus. Nature 222: $282-284,1969$

16. Rice, K. K. and C. P. Richter. Increased sodium chloride and water intake of normal rats treated with desoxycorticosterone acetate. Endocrin. 33: $106-115,1943$

17. Russek, M., A. M. Rodriquez-Zendejas and S. Pina. Hypothetical liver receptors and the anorexia caused by adrenalin and glucose. Physiol. Behav. 3: 249-257, 1968.

18. Russek, M. Hepatic receptors and the neurophysiological mechanisms controlling feeding behavior. In: Neurosciences Research, 4, edited by S. Ehrenpsis. New York: Academic Press, 1971, pp. 214-282.

19. Smith, G. P. and A. M. Epstein. Increased feeding in response to decreased glucose utilization in rat and monkey. Am. J. Physiol. 217: 1083-1087, 1969.

20. Swingle, W. W., C. Baker, M. Eisler, S. J. LeCrie and L. J. Brannick. Efficacy of 9 alpha-halo adrenal steriods for maintenance of adrenalectomized dogs. Proc. Soc. exp. Biol. Med. 88: 193-196, 1955.

21. Wolf, G. Effect of desoxycorticosterone on sodium appetite of intact and adrenalectomized rats. Am. J. Physiol. 208: $1281-1285,1965$.

22. Wolf, G., J. F. McGovern and L. V. DiCara. Sodium appetite: Some conceptual and methodological aspects of a model drive system. Behav. Biol., 1973, In press. 